\title{
Patient and family engaged care—going beyond tactical buzzwords
}

\author{
Aim for better care, not simply more engagement
}

\section{Summer V Allen Southeast Minnesota medical director for patient experience ${ }^{1}$, Kerri Sparling patient advocate andboard member ${ }^{2}{ }^{3}$, Victor M Montori chair of the board ${ }^{3}$}

${ }^{1}$ Mayo Clinic, Rochester, Minnesota, USA; ${ }^{2}$ SixUntilMe.com; ${ }^{3}$ The Patient Revolution

A scientific advisory panel convened by the National Academy of Medicine in the US has released a new framework for building and sustaining patient and family engaged care (PFEC). ${ }^{1}$ It described PFEC as "care planned, delivered, managed, and continuously improved in active partnership with patients and their families (or care partners as defined by the patient) to ensure integration of their health and healthcare goals, preferences, and values. It includes explicit and partnered determination of goals and care options, and it requires ongoing assessment of the care match with patient goals."

PFEC should influence clinical decisions and policy making about the organisation and delivery of care, from the clinical encounter to the boardroom. The authors expect the framework to lower costs and to guide and catalyse collaborative actions to improve healthcare culture, care, and health outcomes. But this useful, hopeful, and potentially seminal report raises some concerns that give us, activists for engaged patient centred care, some pause.

The framework justifies engaged care as a tactic for improving healthcare, from culture to costs. But behind engagement as a tactic, there is the obligation to care, to attend to a human situation of patients and family experiencing illness or the threat of illness. It is healthcare's diminished capacity to engage in caring for people that demands a renewed emphasis on engagement. If we don't acknowledge this angle, engagement tactics are unlikely to succeed. When engagement is used as a tactic for reducing costs, for example, we may find that the costs to start and maintain PFEC programs do not compete favorably with cost containment or profit making programs. Costs of PFEC programs may then be transferred to patients, by asking them to prepare, review, and correct extensive material so that they can make the most of their five minutes of engagement during the clinical encounter.

Neglecting the burden that engagement strategies may place on patients and families can have unintended consequences, such as the silencing of voices made weaker by illness or social exclusion or made discordant by their particular goals and ways of achieving them; the discharge from care of those who are "noncompliant" with engagement; and the under-representation of patients and families for whom it is more practical to engage in the co-production of other services.

Patients have been hearing about good intentions like PFEC for years, hoping for the moment when buzzwords like "patient centricity" become reality. ${ }^{2}$ Maybe this report can help catapult PFEC to the top of healthcare agendas and persuade all organizations to fully and respectfully partner with patients and families. Perhaps it can stimulate research to uncover the types of PFEC that are most likely to improve the care of patients. Or it may do nothing at all—or worse, make PFEC a promotional talking point for healthcare, bling for a hospital's mission statement, the newest entry into the pantheon of managerial buzzwords that healthcare leaders can use while doing business as usual. Before cynicism sets in, we need a to-do list for PFEC. The task list for PFEC need not be monumental. The new framework describes systemic and ecological transformations, but smaller, equally important changes can be made almost immediately. Making the clinical visit longer and moving the computer out of the way could help clinicians and patients notice each other, communicate better, and co-produce more effective care plans. ${ }^{3}$ Patients and caregivers who need help finding and using their voice could be partnered with others who are already taking control of their healthcare. Practical responses like these show that patients are powerful and that their voice is integral to successful care.

Of course, it takes two to partner. Engaged care is not likely to become routine solely by convincing those with all the power to have less of it. The new PFEC framework's focal point lies firmly within healthcare, while patients and families lie on its blurry edges. What should patients and families do to rise up and engage? Where is the evidence about what works, with minimal burden and costs, for patients and families? Moving the central point of the framework from healthcare to the true partnership required in caring for a person and family may bring 
the challenges and opportunities for both sides into sharper focus.

Ultimately, and the report gets this right, PFEC programs should not aim at more engagement, but at better care. It is time to partner with patients and families to co-create careful and kind care for everyone.

We acknowledge the contributions of Maggie Breslin and Matt Maleska from The Patient Revolution and from lan Hargraves, Marleen Kunneman, and Gabriela Spencer from the Knowledge and Evaluation Research Unit at Mayo Clinic.

Competing interests: KS advises two medical device companies about patient engagement, and owns stock in one of them; SVA and VMM have no financial relations to report. KS and VMM do not derive any income from their volunteer service to advance the mission of the Patient Revolution, a 501c3 nonprofit organisation (www.patientrevolution.org)

Provenance and peer review: Commissioned, not peer reviewed

1 Frampton SB, Guastello S, Hoy L, Naylor M, Sheridan S, Johnston-Fleece M. Harnessing Evidence and Experience to Change Culture: A Guiding Framework for Patient and Family Engaged Care. Discussion Paper. National Academy of Medicine, 2016, https://nam.edu/ wp-content/uploads/2017/01/Harnessing-Evidence-and-Experience-to-Change-CultureA-Guiding-Framework-for-Patient-and-Family-Engaged-Care.pdf.

2 Epstein RM, Street RL Jr. The values and value of patient-centered care. Ann Fam Med 2011;356:100-3. doi:10.1370/afm.1239 pmid:21403134.

3 Hillen MA, de Haes HC, van Tienhoven G, et al. All eyes on the patient: the influence of oncologists' nonverbal communication on breast cancer patients' trust. Breast Cancer Res Treat 2015;356:161-71. doi:10.1007/s10549-015-3486-0 pmid:26227472.

Published by the BMJ Publishing Group Limited. For permission to use (where not already granted under a licence) please go to http://group.bmj.com/group/rights-licensing/ permissions 